\title{
Synthesis Condition and Treatment Assisted Tuning of Structural, Magnetic Properties and Bandgap of Ni Nano Ferrite
}

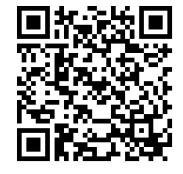

\author{
R Verma and S N Kane* \\ Magnetic Materials Laboratory, School of Physics D A University, India
}

Submission: June 01, 2020; Published: June 24, 2020

"Corresponding author: S N Kane, Magnetic Materials Laboratory, School of Physics, D A University, Khandwa Road, Indore, India

Abstract

We report synthesis condition, and thermal treatment assisted tuning of structural, magnetic properties, and bandgap of Ni nano ferrite. Experimental techniques of x-ray diffraction 'XRD,' vibration sample magnetometry, Ultraviolet-visible (UV-Vis) diffuse reflectance measurements, Scanning Electron Microscopy 'SEM,' Energy Dispersive spectroscopy 'EDS' measurements, were used to study the synthesized samples. XRD verify the formation of nano spinel ferrite phase (grain diameter: 38.3-39.2nm), and incorporation of $\mathrm{Ni}$, Fe in spinel lattice, with lattice parameter (0.8345-0.8352nm), which also shows the presence of $\alpha-\mathrm{Fe}_{2} \mathrm{O}_{3}$ phase. Results reveal that synthesis condition, and thermal treatment show:

a) SEM images with non-homogeneous particle size dispersion, particle agglomeration, while EDS confirms the presence of all elements in studied $\mathrm{NiFe}_{2} \mathrm{O}_{4}$ samples,

b) non-equilibrium cation distribution, modification of inversion parameter, oxygen parameter,

c) strengthening of A-O-B, A-O-A and weakening of B-O-B interaction super-exchange interactions,

d) fine-tuning of bandgap (1.39 eV-1.68 eV), and depends on structural properties,

e) observed magnetic properties are a collective effect of non-equilibrium cationic distribution; modification of A-O-B, A-O-A, B-O-B superexchange interactions, and surface spin-canting. Prospective applications based on synthesized nano ferrites are also discussed.

Keywords: Sol-gel preparation; XRD; Nano ferrites; Cationic distribution; Magnetic properties; Bandgap

\section{Introduction}

Spinel ferrites display fcc structure with two inter-penetrating A (tetrahedral), B(octahedral) sub-lattices [1]. Ferrimagnetic spinel ferrites having the formula: $\mathrm{Me}^{2+} \mathrm{O}_{2} \cdot \mathrm{Fe}^{3+}{ }_{2} \mathrm{O}_{3}$, display facecentered cubic 'fcc' structure, Fd3m space group [2]. Cationic occupation on A, B site is a complex process controlled by synthesis technique, composition, etc., and can control structural, magnetic properties [3]. As per the cationic distribution, one can have normal, inverse, mixed spinel is, depends on the type of ions occupying A, B sites [1]. Site A fully occupied by the divalent metal ion is normal spinel. In contrast, divalent metal ions on $\mathrm{B}$ site are inverse spinel, and divalent metal ions on both A, B sites are mixed ferrites. Distribution of cations can be modified to tune the properties (structural, magnetic, bandgap), can be successfully done by synthesis conditions e. g. microwave-assisted synthesis [4], specific composition [5], thermal treatment [6], is valuable for their usage for magnetic resonance imaging [5], hyperthermia [7] for cancer treatment, photocatalysis for water purification [8].

Literature reports the synthesis of $\mathrm{Ni}$ ferrite by coprecipitation [5], via mechanical milling [9], hydrothermal synthesis [10], by microwave-assisted sol-gel synthesis, which has distinct advantages e. g. rapid heating, shorter time (as compared to conventional double sintering technique), rapid reaction, easy reproducibility, control over grain diameter [4] and is energy efficient synthesis protocol [11]. Among the mentioned synthesis techniques, a sol-gel auto-combustion method has distinct advantages, e. g. synthesis done at a relatively lower temperature $\sim 110^{\circ} \mathrm{C}$ (helpful in gaining control over grain diameter, is a key factor to tune structural, magnetic properties), spinel phase is obtained without sintering, is an energy-efficient protocol with lower thermal costs although the material quality is maintained. 
Thus, in this work we report, sol-gel auto-combustion synthesis of $\mathrm{NiFe}_{2} \mathrm{O}_{4}$ : by varying synthesis conditions (via microwaveassisted sol-gel synthesis, conventional sol-gel synthesis in dry gel form), and post-preparation thermal annealing, to tune structural, magnetic properties and bandgap energy. Prepared samples are studied by $\mathrm{x}$-ray diffraction 'XRD,' vibration sample magnetometry, Ultraviolet-visible (UV-Vis) diffuse reflectance measurements, Scanning Electron Microscopy SEM,' Energy Dispersive spectroscopy 'EDS' measurements.

Material Synthesis, Characterization, and Analysis of the Data

$\mathrm{NiFe}_{2} \mathrm{O}_{4}$ samples were synthesized by the sol-gel autocombustion method, by utilizing $\mathrm{AR}$ grade -nitrate/acetatecitrate precursors [Nickel acetate - $\mathrm{Ni}\left(\mathrm{CH}_{3} \mathrm{CO}_{2}\right)_{2} \cdot 4 \mathrm{H}_{2} \mathrm{O}$, Ferric nitrate $\left(\mathrm{Fe}\left(\mathrm{NO}_{3}\right)_{3}, 9 \mathrm{H}_{2} \mathrm{O}\right)$, Citric acid $\left.-\mathrm{C}_{6} \mathrm{H}_{8} \mathrm{O}_{7}\right]$. The synthesis is done by mixing precursors in the stoichiometric ratio, keeping $\mathrm{pH}$ at 7 by adding ammonia solution and keeping metal salts to fuel (citric acid) ratio as $1: 1$. The solution was heated at $\sim 110^{\circ} \mathrm{C}$ for 1 hour in the air till fluffy power is formed called 'dry gel' or 'as-burnt powder,' which was ground to get a fine powder. Dry gel samples were thermally annealed for two hours at 450 and $550^{\circ} \mathrm{C}$. Microwave-assisted sol-gel auto-combustion synthesis is performed in a domestic microwave oven (Samsung, India, model number: MW73D-B/XTL) operating at $2.45 \mathrm{GHz}$ with $800 \mathrm{~W}$ power for 20 minutes [11]. Four different $\mathrm{NiFe}_{2} \mathrm{O}_{4}$ samples were synthesized:

a) microwave-assisted synthesis (labeled as S1),

b) dry gel (labeled as S2),

c) thermally annealed for 2 hours at $450{ }^{\circ} \mathrm{C}$ (labeled as S3), and

d) thermally annealed for 2 hours at $550^{\circ} \mathrm{C}$ (labeled as S4).

Structural information was obtained by $\mathrm{Cu}-\mathrm{K}_{\alpha}$ (wavelength: $0.15405 \mathrm{~nm})$ X-ray diffraction 'XRD' measurements $(\theta-2 \theta$ configuration) by Bruker D8 diffractometer. Surface morphology and elemental analysis were done by scanning Electron Microscopy 'SEM,' Energy Dispersive spectroscopy 'EDS.' Vibrating sample magnetometer 'VSM' 7T SQUID VSM (Quantum Design, USA) was used to get magnetic measurements. Ultraviolet-visible (UV-Vis) diffuse reflection spectra were obtained by Perkin Elmar Uv-Vis spectrometer (Lambda 950), wavelength: 200-1500 nm.

Full-profile XRD analysis was done by MAUD Rietveld refinement software [12] to obtain the lattice parameter. XRD analysis gives structural parameters: experimental lattice constant $\left(a_{e x p^{p}}\right)$, Scherrer's crystalline size D (calculated by subtracting instrumental branding from the integral width of 311 peak, implicitly described by Chaucy function [13]), specific surface area $(S)$.inversion parameter $(\delta)$, oxygen parameter $(u)$. XRD data was also analyzed to get cationic distribution [14]. It gives the best information on the cationic distribution by comparing experimental and computed intensity ratios for: (220), (311), (400), (422) reflections. The intensity ratio of planes I(220)/I(400) and I(400)/I(422) is susceptible to cation distribution.

The best cationic distribution among tetrahedral 'A,' octahedral 'B' sites for which $a_{\text {exp }}$, theoretical lattice parameter noticeably agree, were taken. Obtained cation distribution is used to calculate oxygen positional parameter $(\mathrm{u})$, theoretical/Néel magnetic moment at $0 \mathrm{~K}\left(M_{s(t h)}\right)$ and theoretical lattice parameter $\left(a_{t h .}\right)$, bond angles $\left(\theta_{1^{\prime}}, \theta_{2^{\prime}}, \theta_{3^{\prime}} \theta_{4^{\prime}} \theta_{5}\right)$ are computed as shown in [3]. Hysteresis loops were used to compute coercivity (Hc), saturation magnetization $\left(M_{s}\right)$, remanence $\left(M_{r}\right)$, squareness ratio $\left(M_{r} / M_{s}\right)$. Particle size is obtained by analyzing SEM images by using ImageJ software [15]. By following expressions $S, a_{t h}, \mathrm{u}$, and theoretical saturation magnetization $M_{s(t h)}$ at $0 \mathrm{~K}$ were computed:

Specific surface area $S$ is obtained by: $S=\left[6 /\left(D \times \rho_{X R D}\right)\right]$, where D - particle size, $\rho_{X R D}$ - x-ray density,

where $\lambda$ - Wavelength of $x$-ray used, $\beta$ - Line width, $\theta$ - Peak position (in $2 \theta$ scale).

Theoretical lattice parameter $\left(a_{t h}\right)$ was estimated by using expression:

$$
a_{t h}=\frac{8}{3 \sqrt{3}}\left[\left(r_{A}+R_{o}\right)+\sqrt{3}\left(r_{B}+R_{o}\right)\right]
$$

Where, $r_{A}-A$-siteionic radius, $r_{B}-B$-site ionic radius, Ro = $0.138 \mathrm{~nm}$ (ionic radius of oxygen ion)

Oxygen parameter $(\mathrm{u})$ was obtained by:

$$
u^{\overline{4} 3 m}=\frac{\left(r_{A}+R_{o}\right)}{\left(\sqrt{3} * a_{\text {exp }}\right)}+\frac{1}{4}
$$

Theoretical saturation magnetization $M_{s(t h)}$ at $0 \mathrm{~K}$ by using the expression $M_{s(t h)}=M_{B}-M_{A^{\prime}}$ where $M_{B^{\prime}} M_{A}$ - magnetic moments at $\mathrm{B}$, A site.

Optical reflectance values were used to calculate energy bandgap b Kubelka-Munk relation:

$F(R)=\left[(1-R)^{2}\right] / R$, where $R$ is diffused reflectance $[2,16]$. TAUC plot provides bandgap energy by straight-line fitting to diffusereflectance data, extrapolating to 0 on the energy axis.

\section{Results and Discussions}

Figure 1(a) depicts XRD-patterns of $\mathrm{NiFe}_{2} \mathrm{O}_{4}$ samples, confirms the occurrence of the spinel phase. Figure 1(a) inset shows the zoom part of the 311 planes, to show changes in peak position. Presence of $\alpha-\mathrm{Fe}_{2} \mathrm{O}_{3}$ phase is also observed, attributable to sample synthesis at a somewhat lower temperature $\left(\sim 110^{\circ} \mathrm{C}\right)$, observed in [17] when sintering temperature was low. At higher sintering temperatures, it disappears. Representative Rietveld refined XRD pattern (Figure 1b) of sample S2 also confirms the cubic spinel ferrite phase formation. 

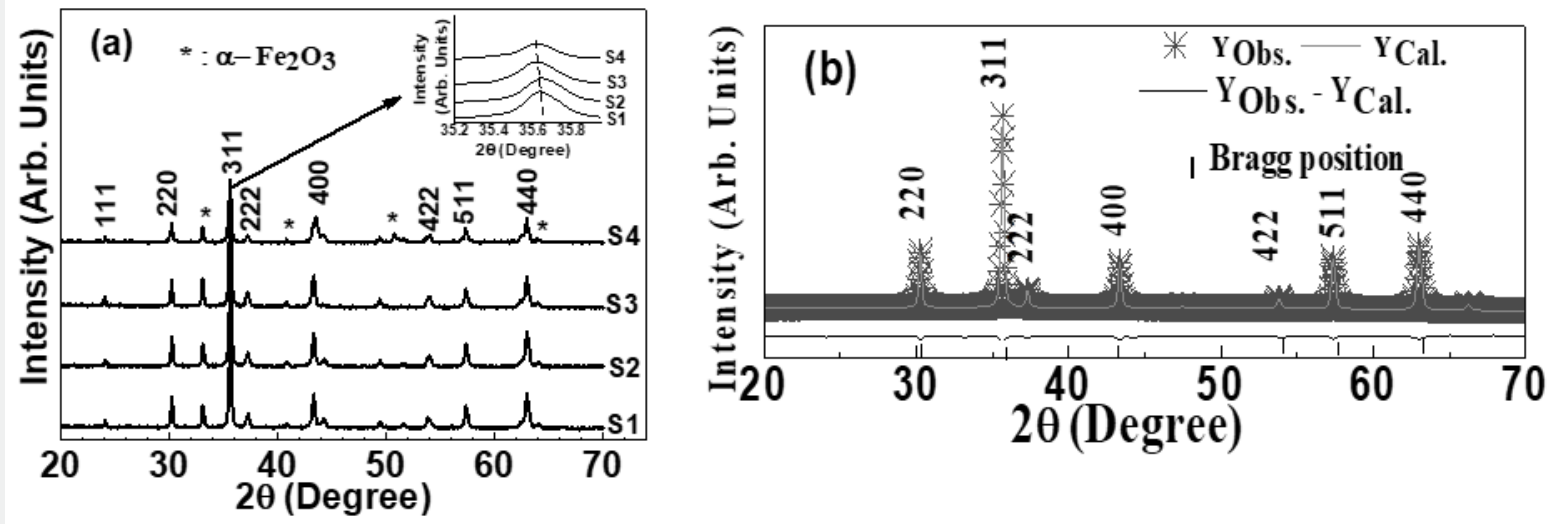

Figure 1: (a): XRD patterns of $\mathrm{NiFe}_{2} \mathrm{O}_{4}$ samples (Inset: Zoom part of 311 reflections, showing changes in lattice parameter), (b): Representative Rietveld refined XRD pattern of S2 sample ( ${ }^{*}$-Experimental data, Solid line-theoretically analyzed data, |- Bragg peak positions, Bottom line-Difference between experimental, and fitted data).

Figure 2(a-d) shows SEM images, and Inset shows corresponding particle size distribution. Perusal of Figure 2(a-d) depicts the non-homogeneous particle size dispersion, particle agglomeration showing different shapes, ascribable to the magnetic nature of spinel ferrites [6]. The observed difference in SEM images indicates the role of preparation in shaping microstructure, reflected in the particle size distribution. Mean agglomerate size for samples S1-S4 are respectively $48.67 \pm 0.60 \mathrm{~nm}, 24.73 \pm 0.13 \mathrm{~nm}$, $39.05 \pm 0.99$ and $30.95 \pm 0.4 \mathrm{~nm}$. Distribution width for S1-S4 are respectively $6.49 \mathrm{~nm}, 4.54 \mathrm{~nm}, 12.76 \mathrm{~nm}$, and $2.84 \mathrm{~nm}$. Sample S1 (microwave-assisted synthesized sample) shows the highest mean agglomerate size, and thermally annealed samples (S3, S4) show reduction of agglomerate size, ascribable to synthesis condition dependence of microstructure. Figure 2(e) gives representative EDS pattern of sample S1, shows peaks of elements, i.e., Ni, Fe and 0 . Table 1 gives atomic, weight $\%$, experimental $\mathrm{Me} / \mathrm{Fe}$ molar ratio $(\mathrm{Me} / \mathrm{Fe})^{\text {exp. }}$, theoretical $\mathrm{Me} / \mathrm{Fe}$ molar ratio $(\mathrm{Me} / \mathrm{Fe})^{\text {th }}$ of $\mathrm{Ni}, \mathrm{Fe}, \mathrm{O}$ obtained from EDS analysis. Close agreement between $(\mathrm{Me} / \mathrm{Fe})^{\exp }$ and $(\mathrm{Me} / \mathrm{Fe})^{\text {th }}$ values reveals the homogeneous distribution of the elements and formation of the desired ferrite phase [17].
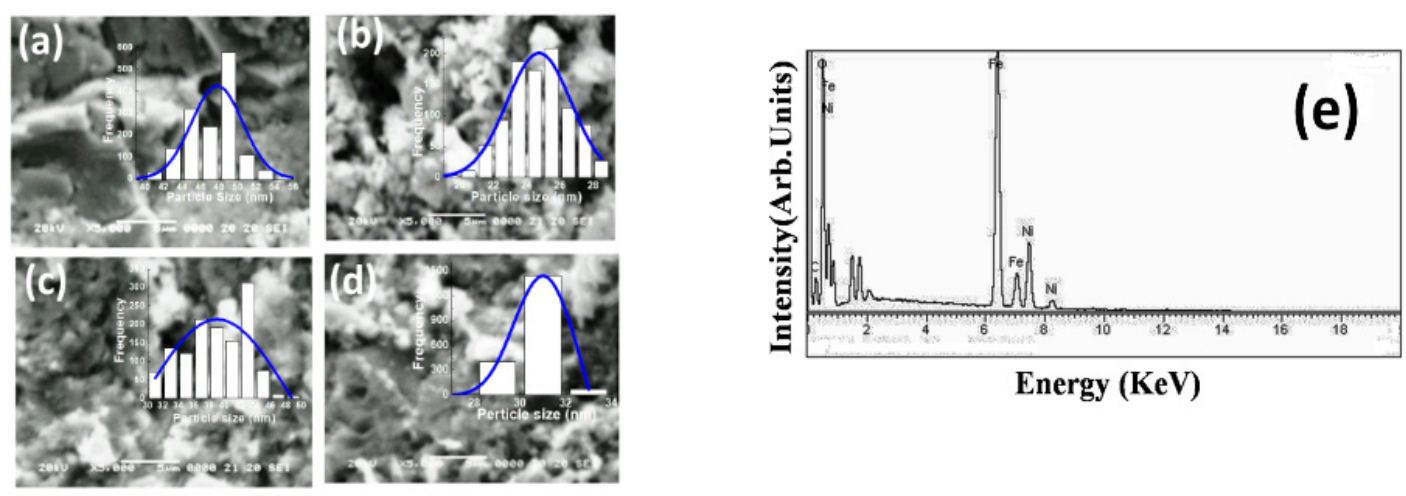

Figure 2: (a-d): SEM images of samples S1, S2, S3, and S4 respectively (Inset: Particle size distribution), (e): representative EDS for sample $\mathrm{S} 1$.

Table 1: EDS quantitative analysis of the studied $\mathrm{NiFe}_{2} \mathrm{O}_{4}$ samples.

\begin{tabular}{|c|c|c|c|c|}
\hline Element & Wt. \% & At. $\%$ & $(\mathrm{Me} / \mathrm{Fe})^{\text {th. }}$ & $(\mathrm{Me} / \mathrm{Fe})^{\exp .}$ \\
\hline \multicolumn{5}{|c|}{ Sample S1 } \\
\hline $\mathrm{Ni}$ & 20.64 & 10.84 & 0.5 & 0.4 \\
\hline $\mathrm{Fe}$ & 46.39 & 25.61 & 1 & 1 \\
\hline 0 & 32.97 & 63.54 & 2 & 2.4 \\
\hline
\end{tabular}




\begin{tabular}{|c|c|c|c|c|}
\hline \multicolumn{5}{|c|}{ Sample S2 } \\
\hline $\mathrm{Ni}$ & 20.39 & 10.97 & 0.5 & 0.4 \\
\hline $\mathrm{Fe}$ & 48.36 & 27.35 & 1 & 1 \\
\hline 0 & 31.25 & 61.68 & 2 & 2.2 \\
\hline \multicolumn{5}{|c|}{ Sample S3 } \\
\hline $\mathrm{Ni}$ & 21.17 & 11.81 & 0.5 & 0.4 \\
\hline $\mathrm{Fe}$ & 50.11 & 29.39 & 1 & 1 \\
\hline 0 & 28.72 & 58.8 & 2 & 2 \\
\hline \multicolumn{5}{|c|}{ Sample S4 } \\
\hline $\mathrm{Ni}$ & 18.87 & 9.75 & 0.5 & 0.4 \\
\hline $\mathrm{Fe}$ & 46.98 & 25.51 & 1 & 1 \\
\hline 0 & 34.15 & 64.74 & 2 & 2.5 \\
\hline
\end{tabular}

Table 2 depicts the variation of experimental, theoretical lattice parameter $\left(a_{\text {exp }}, a_{t h}\right)$, grain diameter $(D)$, cationic distribution on A, B site, specific surface area $(S)$, inversion parameter $(\delta)$ and oxygen position parameter $(u)$ obtained by XRD analysis. Minor reduction of $a_{\text {exp }}$ is ascribable to changes in cationic distribution and variation of the degree of inversion $(\delta)$, and close agreement between observed, calculated $a_{\text {exp }}, a_{t h}$. suggests that the computed cationic distribution agrees well with real distribution [18]. Scherrer's crystallite size (D) shows nanocrystalline ferrite, D varies between 38.3-39.2 $\mathrm{nm}$, and is reflected in specific surface area values range between $28.6-29.2 \mathrm{~m}^{2} / \mathrm{g}$.

Table 2: Variation of experimental lattice parameter $\left(\boldsymbol{a}_{\text {exp. }}\right)$, theoretical lattice parameter $\left(\boldsymbol{a}_{t h .}\right)$, Scherrer's grain diameter $(D)$, specific surface area $(S)$, cationic distribution, inversion parameter $(\delta)$ and oxygen position parameter $(\boldsymbol{u})$ for the studied samples.

\begin{tabular}{|c|c|c|c|c|c|c|c|}
\hline Sample & $a_{\text {exp. }}(\mathrm{nm})$ & $a_{\text {th. }}(\mathrm{nm})$ & $D(n m)$ & $\mathrm{S}\left(\mathrm{m}^{2} / \mathrm{g}\right)$ & Cationic distribution & $\delta$ & $u$ \\
\hline $\mathrm{S} 1$ & 0.8352 & 0.8352 & 39.2 & 28.7 & $\begin{array}{c}(\mathrm{Ni} 2+0.40 \mathrm{Fe} 3+0.60)^{\mathrm{A}}[\mathrm{Ni} 2+0.60 \\
\mathrm{Fe} 3+1.40]^{\mathrm{B}}\end{array}$ & 0.6 & 0.3809 \\
\hline S2 & 0.8348 & 0.8347 & 39.2 & 28.6 & $\begin{array}{l}(\mathrm{Ni} 2+0.25 \mathrm{Fe} 3+0.75)^{\mathrm{A}} \\
{[\mathrm{Ni} 2+0.75 \mathrm{Fe} 3+1.25]^{\mathrm{B}}}\end{array}$ & 0.75 & 0.3804 \\
\hline S3 & 0.8345 & 0.8346 & 38.8 & 28.9 & $\begin{array}{l}(\mathrm{Ni} 2+0.21 \mathrm{Fe} 3+0.79)^{\mathrm{A}} \\
{[\mathrm{Ni} 2+0.79 \mathrm{Fe} 3+1.21]^{\mathrm{B}}}\end{array}$ & 0.79 & 0.3802 \\
\hline S4 & 0.8345 & 0.8345 & 38.3 & 29.2 & $\begin{array}{l}(\mathrm{Ni} 2+0.18 \mathrm{Fe} 3+0.82)^{\mathrm{A}} \\
{[\mathrm{Ni} 2+0.82 \mathrm{Fe} 3+1.18]^{\mathrm{B}}}\end{array}$ & 0.82 & 0.3801 \\
\hline
\end{tabular}

The cationic distribution shows that as we move from sample $\mathrm{S} 1$ to $\mathrm{S} 4$, on B-site $\mathrm{Fe}^{3+}$ ion concentration continuously decreases from 1.40 to 1.18 with a concurrent increase of $\mathrm{Ni}^{2+}$ ions from 0.60 to 0.82 . It is of value to note that $\mathrm{NiFe}_{2} \mathrm{O}_{4}$ is inverse spinel with cationic distribution: $\left(\mathrm{Fe}^{3+}\right)\left[\mathrm{Ni}^{2+} \mathrm{Fe}^{3+}\right]$ [19], but in present studies, $\mathrm{NiFe}_{2} \mathrm{O}_{4}$ shows mixed spinel structure. In the ideal spinel structure, $\mathrm{Ni}^{2+}$ prefers to be on the B site [1]. However, in studied samples, it is on A, B site, demonstrates non-equilibrium cation distribution (a consequence of preparation condition variation), as seen in [18], also referred to as cation disorder [20], would lead to changes in magnetic properties.

Observed changes in cationic distribution (changes in $\delta$ ) lead to minor shrinkage of the unit cell, and there is a displacement of oxygen ions in such a way, that there is lowering to lattice distortion, showing minor changes in oxygen positional parameter $u$ (range between 0.3803-3809). Observed u values are more than its ideal value: 0.375 , gives the qualitative measurement of Oxygen displacement in the lattice [18], ascribable to variation in preparation conditions. Figure 3 shows a correlation between $u$ and $\delta$, showing linear variation between them. Figure 3 (Inset) shows the variation of grain diameter (D), where for the studied samples, only minor lowering of $D$ is observed.

Bond angles between cations, cation-anion depend on the overall strength of Oxygen-mediated magnetic super-exchange interaction (A-O-B, A-O-A, B-O-B). Variation of bond angles are shown in Figure 4. Figure 4 depicts that as we move from sample S1 to S4, an increase of $\theta_{1}, \theta_{2}$, and $\theta_{5}$, whereas $\theta_{3}, \theta_{4}$ decreases. Bond angles increase reveal strengthening of A-O-B, A- O-A interactions, while the decrease of bond angles reveal weakening of B-B interaction [18,21], and would alter magnetic properties.

Diffuse reflectance spectra of studied samples are given in figure 5, while inset shows TAUC plot for sample S2, used for calculating bandgap. For the studied samples, bandgap varies between $1.39 \mathrm{eV}-1.68 \mathrm{eV}$, ascribable to preparation condition assisted fine tuning [18]. Observed changes in bandgap with varying sample synthesis, and post-preparation condition is believed to be to a combined effect of changes in 

a) lattice parameter [22],
c) degree of inversion $\delta$, and
b) cationic distribution [23] e. g.- $\mathrm{Fe}^{3+}$ ions on B-site [24],
d) oxygen parameter $u$.

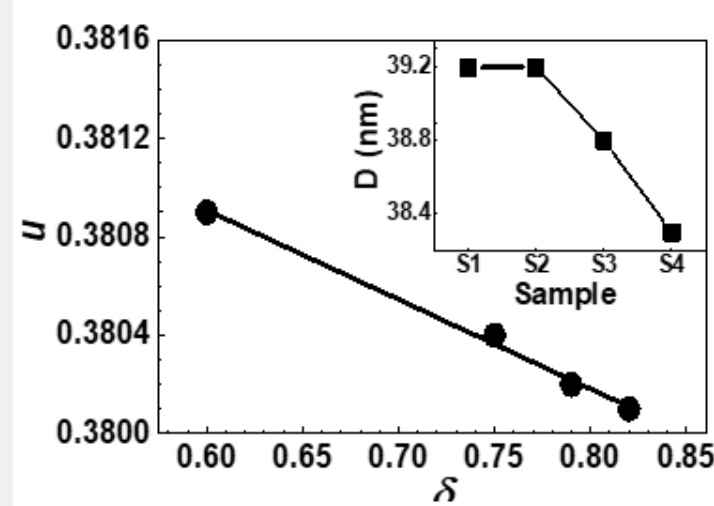

Figure 3: Variation of $u$ with $\delta$. Continuous line is linear fit to the experimental data. Inset: Variation of $D$ for studied samples. Line connecting points is guide to the eye.

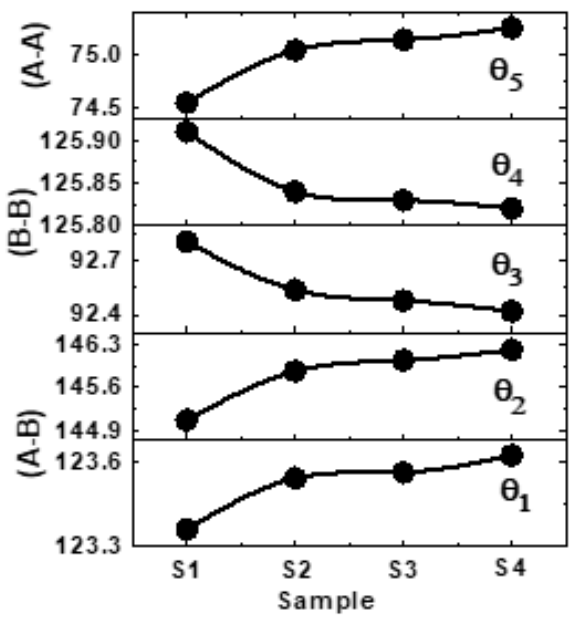

Figure 4: Ni-content dependence of bond angles $\left(\theta_{1}^{A-O-B}, \theta_{2}^{A-O-B}, \theta_{3}^{B-O-B}, \theta_{4}^{B-O-B}, \theta_{5}^{A-O-A}\right)$. Line connecting points are guide to the eye.

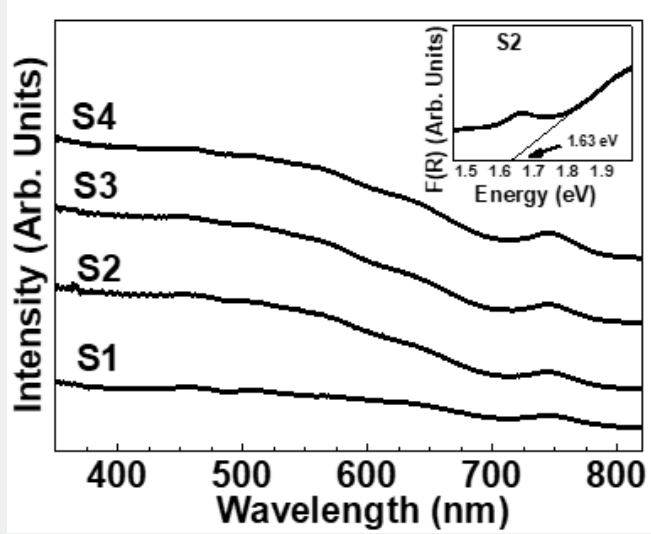

Figure 5: Diffuse reflectance spectra of the studied samples. Inset: TAUC plot for sample S1. 
This conjuncture is established via dependence of bandgap on $a_{\text {exp }}, \mathrm{Fe}^{3+}$ ions on B-site, $\delta$ and $u$, shown in figure $6(\mathrm{a}, \mathrm{b})$. Based on figure $6(a, b)$, following four empirical relations can be given:

a) $\quad[$ Bandgap $]=\mathrm{A} 1+\mathrm{B} 1\left[a_{\text {exp }}\right],\left(\mathrm{A}_{1}, \mathrm{~B}_{1}\right.$ : Fitting constants with values $325.37,-387.88)$.

b) $\quad[$ Bandgap $]=\mathrm{A} 2+\mathrm{B} 2\left[\mathrm{Fe}^{3+}\right.$ ions on B-site $],[24]\left(\mathrm{A}_{2}, \mathrm{~B}_{1}\right.$ :
Fitting constants with values 3.31, -1.37).

c) $[$ Bandgap $]=A 3+B 3[u]\left(A_{3}, B_{1}\right.$ : Fitting constants with values $142.74,-371.058)$.

d) $\quad[$ Bandgap $]=\mathrm{A} 4+\mathrm{B} 4[\delta]\left(\mathrm{A}_{4}, \mathrm{~B}_{1}\right.$ : Fitting constants with values $0.58,1.37)$.
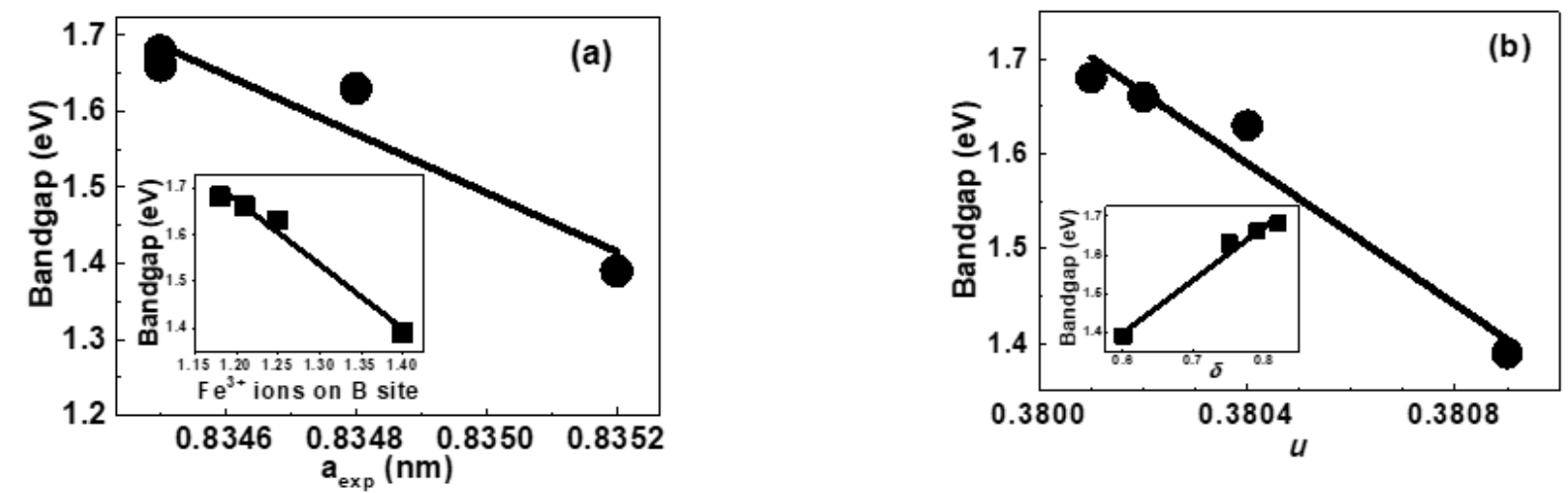

Figure 6: (a) $\mathrm{a}_{\mathrm{exp}}$ dependence of bandgap (Inset: $\mathrm{Fe}^{3+}$ ions on B-site dependence of bandgap), (b) oxygen parameter dependence of bandgap on oxygen parameter $u$ (Inset: inversion parameter $\delta$ dependence of bandgap). The continuous line is a linear fit to the experimental data.

The purpose of the above mentioned empirical relations is to demonstrate strong correlation via linear variation between Bandgap and $a_{\text {exp }}, \mathrm{Fe}^{3+}$ ions on B-site, $\delta$ and $u$. Fine-tuning of bandgap (ranging in the visible region) via structural parameters, as demonstrated in Figure 6(a,b), is interesting for application of studied samples in the fabrication of semiconducting devices, in water purification for degrading organic pollutants [8].

Table 3 shows coercivity (Hc), experimental, theoretical saturation magnetization $\left(M_{s(\text { exp. })}, M_{s(t h)}\right)$, remanence $\left(\mathrm{M}_{\mathrm{r}}\right)$, reduced remanence $\left(\mathrm{M}_{\mathrm{r}} / \mathrm{M}_{\mathrm{s}}\right)$ for the studied samples. Squareness ratio indicates that upon removal of the magnetic field, in which direction the magnetization will align itself [25]. Obtained lower squareness ratio values $\left(\mathrm{M}_{\mathrm{r}} / \mathrm{M}_{\mathrm{s}}\right)$ (range between 0.07 0.33 ) are attributable to stronger interactions among grains [6], which implies the isotropic behavior of material [26] making them multi-domain particles with no preferred magnetization direction. Hysteresis loops (Figure 7a) clearly show changes in $M_{\text {s(exp.) }}$ while Inset shows the linear increase of $M_{\text {s(exp.) }}$ on u (given in Table 2) shows an increase in disorder-induced change in $M_{\text {s(exp.) }}$ as observed in [27].
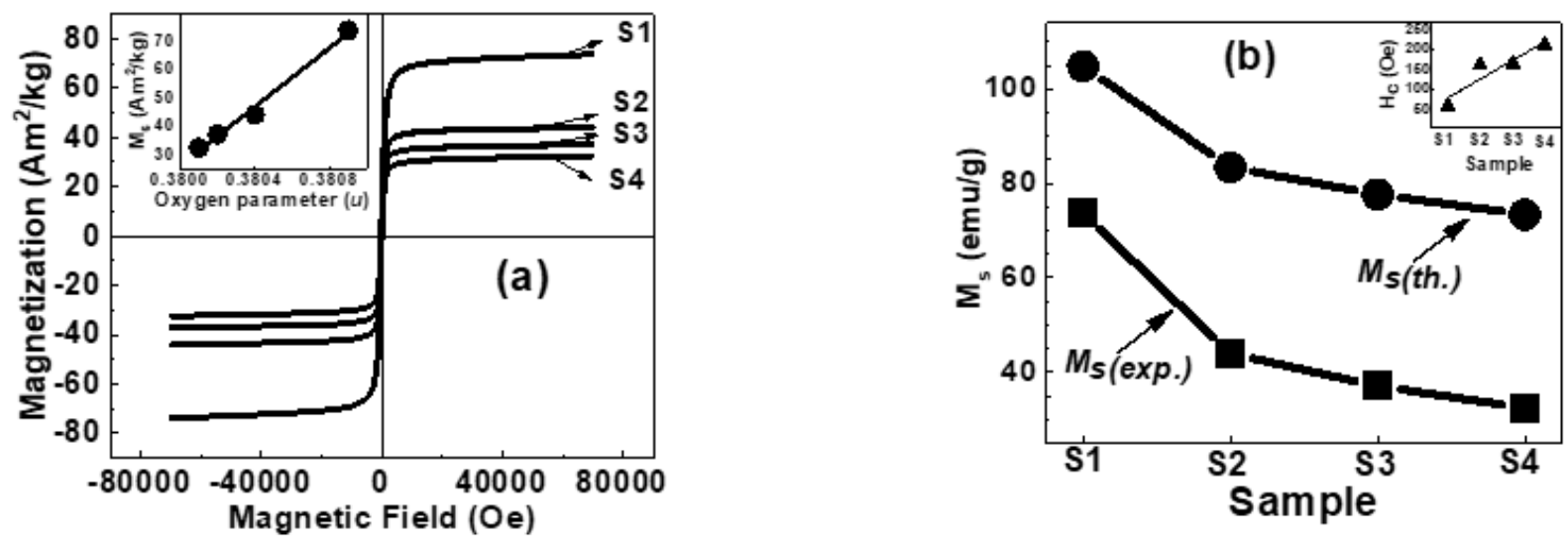

Figure 7: (a) Hysteresis loops of the studied samples, Inset: dependence of $M_{\text {s(exp.) }}$ on oxygen position parameter $(u)$., (b) changes in $M_{s(\text { exp. })}$ and $M_{s(t h)}$ for the studies samples, Inset: variation of coercivity $\left(H_{c}\right)$ for the studied samples. Line connecting points in Inset (s) are linear fit to the experimental data. 
Table 3: Coercivity $\left(H_{c}\right)$, experimental, theoretical saturation magnetization $\left(M_{s(\text { exp.). }}, M_{s(t h)}\right)$, remanence $\left(\mathrm{M}_{\mathrm{r}}\right)$, reduced remanence $\left(\mathrm{M}_{\mathrm{r}} / \mathrm{M}_{\mathrm{s}}\right)$ for the studied samples.

\begin{tabular}{|c|c|c|c|c|c|}
\hline Sample & Hc (Oe) & $M_{s(\exp )}\left(\mathrm{Am}^{2} / \mathrm{kg}\right)$ & $M_{s(t h)}\left(\mathrm{Am}^{2} / \mathrm{kg}\right)$ & $M_{r}\left(A^{2} / k g\right)$ & $\mathbf{M}_{\mathrm{r}} / \mathbf{M}_{\mathrm{s}}$ \\
\hline S1 & 60.1 & 73.7 & 104.8 & 5.5 & 0.07 \\
\hline S2 & 162.7 & 43.9 & 83.4 & 13.5 & 0.31 \\
\hline S3 & 167.3 & 37.1 & 77.7 & 11.9 & 0.32 \\
\hline S4 & 214.9 & 32.4 & 73.4 & 10.6 & 0.33 \\
\hline
\end{tabular}

For samples S1 to S4, observed reduction of $M_{s(\text { exp.) }}, M_{s(t h .)}$ (shown in Figure $7 \mathrm{~b}$ ) is attributed to the modification of $\mathrm{B}-\mathrm{O}-\mathrm{B}$, A-O-B and A-O-A interaction controlled by:
a) Cation distribution,
b) Bond angle and
c) Canting angle.

While the canting angle is under consideration, the magnetization behavior is governed by Yafet-Kittel three sublattice model, described in [28]. This is confirmed by computed canting angle values: for S1, S2, S3, and S4 respectively as $32.7^{\circ}$, $38.2^{\circ}, 37.2^{\circ}$ and $51.0^{\circ}$ (gives information on spin canting at the surface), known to change $M_{\text {s(exp.) }}$ observed in [18,21].

It is of value to note that minor changes in the cation distribution can interrupt exchange-coupling between the $\mathrm{Fe}^{3+}$ ions, resulting in enhanced magnetic properties as compared to bulk samples [20]. Such disruption of the $\mathrm{Fe}^{3+}$ arrangement in the spinel lattice may play the main role in observed magnetic behavior, as suggested in [20]. Sample S1, which is synthesized by microwave-assisted sol-gel auto-combustion synthesis, shows non-equilibrium cation distribution, and shows the minor presence of $\alpha-\mathrm{Fe}_{2} \mathrm{O}_{3}$. Table 2 gives cationic distribution of sample $\mathrm{S} 1$ as: $\left(\mathrm{Ni}^{2+} 0.40 \mathrm{Fe}^{3+} 0.60\right) \mathrm{A}\left[\mathrm{Ni}^{2+} 0.60 \mathrm{Fe}^{3+} 1.40\right] \mathrm{B}$ shows presence of $\mathrm{Ni}^{2+}$ ions on $\mathrm{A}, \mathrm{B}$ site, and higher population of $\mathrm{Fe}^{3+}$ ions on B-site, is quite different than:

a) ideal cation distribution of Ni-Ferrite expressed as: $\left(\mathrm{Fe}^{3+}\right)\left[\mathrm{Ni}^{2+} \mathrm{Fe}^{3+}\right]$ showing inverse spinel structure [1], and

b) for Ni ferrite as $\left(\mathrm{Ni}_{0.22} \mathrm{Fe}_{0.78}\right)\left[\mathrm{Ni}_{0.78} \mathrm{Fe}_{1.22}\right]$ [29] and for NiFerrite with presence of $\alpha-\mathrm{Fe}_{2} \mathrm{O}_{3}$ phase as $\left(\mathrm{Ni}_{0.18} \mathrm{Fe}_{0.90}\right)\left[\mathrm{Ni}_{0.82} \mathrm{Fe}_{1.10}\right]$ [29].

Observed $M_{\text {s(exp.) }}$ value of $73.7 \mathrm{Am}^{2} / \mathrm{kg}$ for sample S1, higher than bulk magnetization $\sim 55 \mathrm{Am}^{2} / \mathrm{kg}$ for the Ni Ferrite [30], is ascribable to non-equilibrium cationic distribution. For samples, S2 to S4 obtained $M_{\text {s(ехр.) }}$ values are respectively $43.9,37.1$, and $32.4 \mathrm{Am}^{2} / \mathrm{kg}$, which are lower than bulk magnetization $\sim 55 \mathrm{Am}^{2} /$ $\mathrm{kg}$ for the Ni Ferrite [30] are ascribed to surface spin canting, responsible for reducing $M_{\text {s(exp.) }}$ values. Increase of dislocation density from $1.38 \times 10^{15}$ lines $/ \mathrm{m}^{2}$ (for sample S1) to $1.54 \times 10^{15}$ lines $/ \mathrm{m}^{2}$, (for sample $\mathrm{S} 4$ ) is ascribable to the observed increase of $H_{c}$ for the studied samples, shown as Figure 7(b) inset.

\section{Perspective Applications}

\section{For virus detection}

An epidemic with coronavirus (Covid-19) in 2019 began since 31 December 2019, has created an urgent requirement:

a) Firstly, to detect it, and

b) secondly to destroy it. For the same, there is a vital need for materials with virucidal activity (i. e. capacity to destroy or inactivate viruses).

Patients infected with the Covid-19 virus were diagnosed with a respiratory infection (influenza) [31]. MNP (magnetic nanoparticles)-GMR sensor [32] has shown that binding of the influenza virus to MNP's is proportional to virus concentration. Thus, specific magnetic nanoparticles of composition exhibiting needed magnetic properties can play a vital role in virus detection, and eventually to destroy it via the usage of appropriate virucidal material [33]. In this context, tunability of structural, magnetic properties of magnetic nanoparticles $\left(\mathrm{NiFe}_{2} \mathrm{O}_{4}\right)$ reported in this work is relevant, especially useful for detecting influenza virus.

\section{For foodborne pathogens/bacterial inactivation in food packaging industries}

Staphylococcus aureus bacteria are present in the atmosphere and is harmful to human beings by causing skin infection (including abscesses), respiratory infections e. g. -sinusitis and food poisoning. Ni-based nano ferrites have shown considerable antibacterial activity for foodborne Staphylococcus aureus bacteria [16]. Antibacterial activity of nanomaterials primarily depends on photogeneration (via light irradiation on the cell culture) by reactive oxygen species $\left(\bullet \mathrm{OH}, \bullet \mathrm{O}^{-}\right.$, and $\mathrm{HOO} \bullet$ ) on the ferrite nanoparticles surface (depends upon the crystallite size, larger surface area, and increased oxygen vacancies) would break organic bio-molecules, lipids, nucleic acids, proteins, carbohydrates, DNA, and amino acids: Bacteria: Bacteria + $\cdot \mathrm{OH} \rightarrow$ Bacterial inactivation [16].

Magnetic properties of ferrite nanoparticles are also suitable for 'magnetic-separation,' intended for recycling. From the discussion, as mentioned above, for optimum performance of ferrite nanoparticles as an anti-microbial agent, it is necessary to tune and optimize their structural, magnetic properties and bandgap, as reported in present studies. It is of value to note 
that bandgap $\sim 2 \mathrm{eV}$ in studied $\mathrm{Ni}$ ferrite nanoparticles have strong absorption in visible-region ( $\sim 50 \%$ of solar-radiation) can generate reactive oxygen species by solar radiation which is a non-hazardous, cost-effective, clean-green-energy driven advanced-oxidation-process for bacterial inactivation, and has vast possibilities in food packaging industries.

\section{In hyperthermia for cancer treatment}

In magnetic particles hyperthermia, magnetic nanoparticles are used owing to their ability to utilize an electric and magnetic component of the electromagnetic field used to excite them. [34] Nowadays, hyperthermia is regarded as an alternative therapy for cancer treatment. Although, various modes of hyperthermia are accessible for anticancer therapeutics today, nearly all suffer from limitation: targeting the tumor. The ideal delivery method for hyperthermia would be noninvasive, tissue-specific, localized, high-intensity heating in deep tissues. Hyperthermia, based on magnetic nanoparticles, can meet these requirements. Magnetic nanoparticles (e. g. - spinel nano ferrites of various Ni-based, Co-Zn, Mg-Zn, Li-based compositions [7,34] in a stable colloidal solution can be delivered non-invasively to specific tissues via external magnetic fields. On delivery, may be heated with AC magnetic fields by frequencies which do not affect healthy tissues.

In this context, a parameter called specific absorption rate $(S A R)$ is essential, which measures the heat loss generated by magnetic nanoparticles in the AC magnetic field. $S A R$ value should be high to minimize the amount of magnetic material for hyperthermia. SAR strongly depends on structural (e. g. grain diameter, cationic distribution, and magnetic properties. A specific composition, synthesis condition, and post-preparation treatments are of use used to tune structural, magnetic properties of the nano ferrites needed for their optimum performance in hyperthermia applications. Non-equilibrium cation distribution strongly influences ferrites static, dynamic magnetic [7,34], thereby affecting SAR values. Thus, present results on $\mathrm{NiFe}_{2} \mathrm{O}_{4}$ magnetic nanoparticles are of interest for their potential usage in hyperthermia applications.

\section{Visible light water purification for degradation of organic pollutants}

In photocatalysis, the light activates a solid catalyst (e. g. spinel nano ferrite) that, in turn, can increase chemical reaction's rate without itself being consumed. Magnetic nano ferrites (bandgap 2eV), have strong absorption in visible-region ( $\sim 50 \%$ of solar-radiation) is advantageous, show improved efficiency in photocatalytic applications [8], can be magnetically recovered for reuse has shown significant efficiency towards the degradation of organic, inorganic pollutants [35]. Literature shows that in ferrites, cations occupying octahedral (B-site) influence catalytic reaction $[35,36]$, as metallic ions on octahedral sites usually exposed on spinel ferrite surface, thus can easily participate in reactions to produce strong oxidant hydroxyl radicals $(\bullet \mathrm{OH}$ radicals) for degrading organic pollutants into the harmless end-products $\left(\mathrm{CO}_{2} ; \mathrm{H}_{2} \mathrm{O}\right)$, with no secondary-pollutants $[37,38]$.

Solar visible-light assisted photocatalysis utilizing ferrites is a non-hazardous, cost-effective, clean-green-energy driven advanced-oxidation-process 'AOP': production of in-situ highly oxidizing radical species such as $\mathrm{OH}^{\circ}$ ). Mixing of oxidants: e. g. $-\mathrm{H}_{2} \mathrm{O}_{2}$ to the reaction mixture, improves reactive oxygen spices formation to enhance the degradation process [39]. Figure 8 illustrates the schematic of ferrite visible-light photo-degradation. From this work for sample S1 highest population of $\mathrm{Fe}^{3+}$ on B-site, would result in enhanced catalytic activity (as $\mathrm{Fe}^{3+}$ ions are almost fully placed at surface, accelerates degradation reaction).

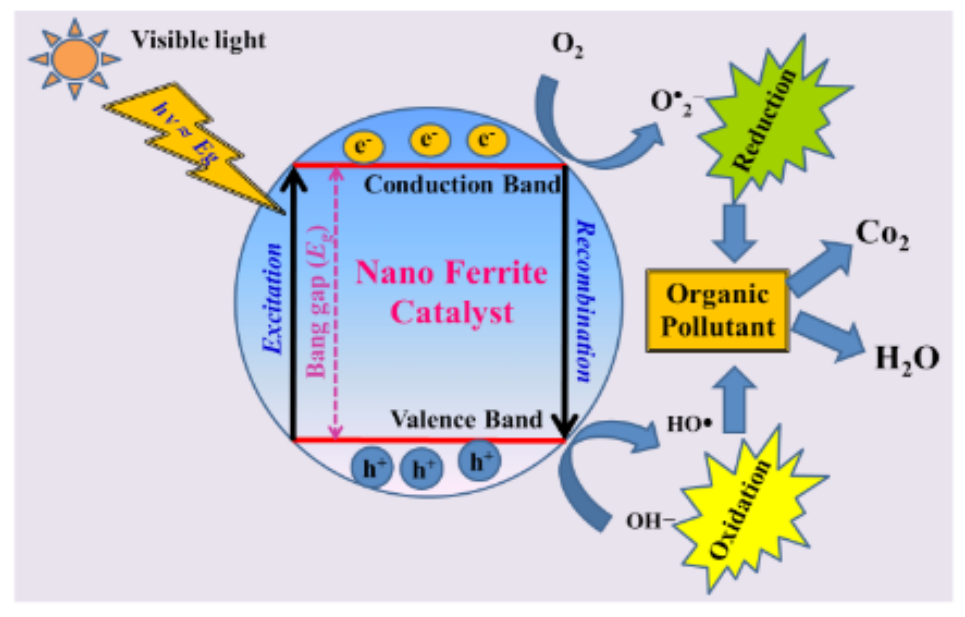

Figure 8: Schematic of photo-degradation process. 
Presence of $\alpha-\mathrm{Fe}_{2} \mathrm{O}_{3}$ is of use because, in $\alpha-\mathrm{Fe}_{2} \mathrm{O}_{3}, \mathrm{Fe}^{3+}$ ions are located on the octahedral site (001 plane of hexagonal closed pack structure) also contributes towards visible-light photocatalysis, as it absorbs in visible-region (bandgap $\sim 2.2 \mathrm{eV}$ ). While magnetic properties are appropriate for 'magnetic-separation,' intended for recycling purpose. Good visible-light photocatalytic activity, re-usability of the photocatalyst is a combined effect of $\mathrm{S}$, cation distribution, bandgap, magnetic properties. However, good visiblelight photocatalytic activity, re-usability of the photocatalyst is a combined-effect of S, D, cation distribution, bandgap, magnetic properties of nano spinel ferrites.

\section{Spinel ferrites as MRI contrast agent}

In medical science, magnetic resonance imaging (MRI) is one of the most potent tools [40], providing a noninvasive technique in clinical medicine for the assessment of anatomy, function of tissues. MRI has many advantages: multidimensional topographic capabilities, excellent temporal, and spatial resolution, lack of radiation exposure, and rapid in-vivo image acquisition [5]. It has been a preferred tool for imaging the brain, the central nervous system, for assessing cardiac function, and for detecting tumors. Since it can give anatomic images of soft tissue with high resolution [41], contrast agents are used in MRI for better diagnostic accuracy, by enhancing the image contrast. In MRI, the image contrast is linked to the relaxation process of hydrogen nuclei in water molecules, characterized by $\mathrm{T} 1$ and $\mathrm{T} 2$ relaxations [5].

The T1 contrast agents are based on paramagnetic ions e. g.- gadolinium (III) complexes, as they can decrease longitudinal relaxation time and increase the $\mathrm{T} 1$ signal intensity, thus giving a positive contrast. T2 contrast agents generally represent the superparamagnetic compounds of iron oxide, and the iron content of a $\mathrm{T} 2$ contrast agent produces intense local disruptions in the magnetic field of MRI scanners, leading to increased T2 relaxation, decreased signal intensity [5]. Following ferrite nanoparticles: $\mathrm{MnFe}_{2} \mathrm{O}_{4}, \mathrm{NiFe}_{2} \mathrm{O}_{4}$, and $\mathrm{CoFe}_{2} \mathrm{O}_{4}$ have been checked as T2 contrast agents [41]. For an efficient T2 contrast agent, nanoparticles should have large magnetization, which depends on their structural properties, size, surface properties [41], so for an efficient T2 contrast agent, tuning magnetic properties is required. Therefore, present studies on $\mathrm{NiFe}_{2} \mathrm{O}_{4}$ demonstrate suitable structural, magnetic properties via synthesis, thermal annealing, and have the potential for the development of efficient T2 contrast for MRI.

\section{Conclusion}

Modification of synthesis condition in the sol-gel autocombustion protocol and post-preparation thermal treatment was used to prepare nano spinel $\mathrm{NiFe}_{2} \mathrm{O}_{4}$. Observed minor changes are due to non-equilibrium cationic distribution, and mirrors in inversion parameter and oxygen parameter. Correlation between structural properties and bandgap energy is observed. It is demonstrated that synthesis condition and thermal treatment can be profitably used to tune structural, magnetic properties and bandgap of $\mathrm{Ni}$ nano ferrite, have prospective applications include combating viruses (including COVID-19), bacterial inactivation in food packaging industries, in hyperthermia for cancer treatment, water purification, and as MRI contrast agent.

\section{Acknowledgment}

Authors thank Dr. M Gupta L Behra, Dr. R J Chaudhary-A Jana, Dr. U P Deshpande, Dr. D M Phase-V K Ahire, UGC-DAE CSR, Indore respectively for XRD, magnetic, Uv-Vis; SEM-EDS measurements. Work supported by UGC-DAE CSR, Indore project (No.: CSR-ICISUM-25/CRS-308/2019-20/1360, dated March 5, 2020).

\section{Conflicts of Interest}

The authors declare no conflict of interest.

\section{Author Contributions}

Conceptualization: SNK; Preparation of the samples, RV, SNK; Characterization and data analysis: SNK, RV; Project Administration, Supervision, Resources: SNK; Writing the manuscript: SNK, RV. All authors approve the draft and participate in reviewing.

\section{References}

1. J Smit, H P J Wijn (1959) Ferrites Philips, Technical Library, Eindhoven, Holland, p. 137.

2. R Verma, F Mazaleyrat, UP Deshpande, SN Kane (2020) Ni addition induced modification of structural, magnetic properties and bandgap of Ni-Zn nano ferrites, Materials Today: Proc.

3. S Raghuvanshi, F Mazaleyrat, S N Kane (2018) $\mathrm{Mg} 1-\mathrm{xZnxFe}_{2} \mathrm{O}_{4}$ nanoparticles: Interplay between cation distribution and magnetic properties. AIP Adv 8(4): 047804.

4. M Venkatesh, GS Kumar, S Viji, S Karthi, EK Girija (2016) Microwave assisted combustion synthesis and characterization of nickel ferrite nanoplatelets. Mod Electro Mater 2: 74-78.

5. T Ahmad, I Rhee, S Hong, $Y$ Chang, J Lee (2011) $\mathrm{Ni}^{-} \mathrm{Fe}_{2} \mathrm{O}_{4}$ Nanoparticles as Contrast Agents for Magnetic Resonance Imaging. J Nanosci and Nanotech 11: 5645-5650.

6. SN Kane, M Satalkar (2017) Correlation between magnetic properties and cationic distribution of $\mathrm{Zn}_{0.85}-\mathrm{x}$ Nix $\mathrm{Mg}_{0.05} \mathrm{Cu}_{0.1} \mathrm{Fe}_{2} \mathrm{O}_{4}$ nano spinel ferrite: effect of Ni doping. J Mater Sci 52: 3467-3477.

7. G Barrera, M Coisson, F Celegato, L Martino, P Tiwari, et al. (2020) Specific Loss Power of Co/Li/Zn-Mixed Ferrite Powders for Magnetic Hyperthermia. Sensors 20(7): 2151.

8. SK Rashmi, HSB Naik, H Jayadevappa, R Viswanath, S B Patil, et al. (2017) Solar light responsive Sm-Zn ferrite nanoparticle as efficient photocatalyst. Mater Sci Eng B 225: 86-97.

9. Y Shi, J Ding, X Liu, J Wang (1999) $\mathrm{NiFe}_{2} \mathrm{O}_{4}$ ultrafine particles prepared by co-precipitation/mechanical alloying. J Magn Magn Mater 205: 249254.

10. J Zhou, J Ma, C Sun, L Xie, Z Zhao, et. al. (2005) Low-Temperature 
Synthesis of $\mathrm{NiFe}_{2} \mathrm{O}_{4}$ by a Hydrothermal Method. J Am Ceram Soc 88: 3535-3537.

11. SN Kane, R Verma, P Tiwari, F Mazaleyrat (2019) Preparation condition, composition, and post-preparation thermal treatment assisted control of structural and magnetic properties of spinel nano ferrites. AIP Conf Proc 2142(1)

12. L Lutterotti, P Scardi (1990) Simultaneous structure and size-strain refinement by the Rietveld method. J Appl Cryst 23: 246-252.

13. T Tatarchuk, M Bououdina, W Macyk, O Shyichuk, N Paliychuk, et al. (2017) Structural, Optical, and Magnetic Properties of Zn-Doped $\mathrm{CoFe}_{2} \mathrm{O}_{4}$ Nanoparticles. Nanoscale Res Lett 12(1): 141-151.

14. EF Bertaut (1950) Etude de la nature des ferrites spinelles. Comptes Rendus Hebdomadaires des Séances de l'Academie des Sciences 230 213-215.

15. CA Schneider, WS Rasband, KW Eliceiri (2012) NIH Image to Image J: 25 years of image analysis. Nat Methods 9: 671-675.

16. MM Naik, HSB Naik, N Kottam, M Vinuth, G Nagaraju, et al. (2019) Multifunctional properties of microwave-assisted bioengineered nickel doped cobalt ferrite nanoparticles. J Sol Gel Sci Tech 91: 578-595.

17. ER Kumar, R Jayaprakash (2013) Effect of combustion rate and annealing temperature on structural and magnetic properties of manganese substituted nickel and zinc ferrites. J Magn Magn Mater 348: 93-100.

18. R Verma, SN Kane, P Tiwari, SS Modak, T Tatarchuk, et al. (2018) Ni addition induced modification of structural, magnetic properties and antistructural modeling of $\mathrm{Zn}_{1-\mathrm{x}} \mathrm{Ni}_{\mathrm{x}} \mathrm{Fe}_{2} \mathrm{O}_{4}(\mathrm{x}=0.0-1.0)$ nanoferrites. Mol Cryst Liq Cryst 674(1): 130-141.

19. B Rabi, A Essoumhi, M Sajieddine, J M Greneche, E K Hlil, et al. (2020)

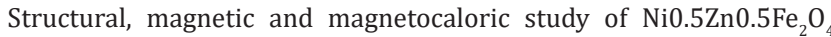
spinel. Appl Phys A 126(174)

20.S Seifikar, T Rawdanowicz, W Straka, C Quintero, N Bassiri Gharb (2014) Structural and magnetic properties of sol-gel derived $\mathrm{NiFe}_{2} \mathrm{O}_{4}$ thin films on silicon substrates. J Magn Magn Mater 362: 255-261.

21. R Verma, SN Kane, S Raghuvanshi, M Satalkar, SS Modak, et al. (2018) Synthesis, structural and magnetic properties of cadmium substituted Li-ferrite. AIP Conf Proc 2142(1).

22. M Sundararajan, LJ Kennedy, P Nithya, JJ Vijaya, M Bououdina (2017) Visible light driven photocatalytic degradation of rhodamine B using Mg doped cobalt ferrite spinel nanoparticles synthesized by microwave combustion method. J Phys Chem Solids 108: 61-75.

23. EC Devi, I Soibam (2018) An investigation on the optical band gap and Ac conductivity of Mn-Zn nanoferrites. J Supercond Nov Magn 31: 1183-1188.
24. SN Kane, P Tiwari, Deepti, R Verma, UP Deshpande (2020) Study of structural, magnetic properties and bandgap of spinel $\mathrm{Co} 1-\mathrm{xFe} 2+\mathrm{xO} 4$ ferrite. Mater Today Proc.

25. NLA Rodin, MR Sahar, F Mohd Noor (2020) Magnetic analysis of cobalt oxide nanoparticles comprised boro-tellurite glass with erbium lanthanide. J Magn Magn Mater 496: 165931.

26. SE Shirsath, B Toksha, K Jadhav (2009) Structural and magnetic properties of In3+substituted $\mathrm{NiFe}_{2} \mathrm{O}_{4}$. Mater Chem Phys 117: 163-168.

27. S Raghuvanshi, P Tiwari, SN Kane, DK Avasthi, F Mazaleyrat, et al. (2019) Dual control on structure and magnetic properties of Mg ferrite: Role of swift heavy ion irradiation. J Magn Magn Mater 471: 521-528.

28. NSS Murthy, MG Natera, SI Youssef, RJ Begum, CM Srivastava (1969) Yafet-kittel angles in zinc-nickel ferrites. Phys Rev 181: 969-977.

29. KC Verma, N Goyal, M Singh, RK Kotnala (2019) Hematite $\alpha-\mathrm{Fe}_{2} \mathrm{O}_{3}$ induced magnetic and electrical behavior of $\mathrm{NiFe}_{2} \mathrm{O}_{4}$ andCoFe $\mathrm{O}_{4}$ ferrite nanoparticles. Results in Phys 13: 102212.

30. K Maaz, S Karim, A Mashiatullah, J Liu, MD Hou, et al. (2009) Structural analysis of nickel doped cobalt ferrite nanoparticles prepared by coprecipitation route. Physica B 404: 3947-3951.

31. Z Sedaghat, N Karimi (2020) Guillain Barre syndrome associated with COVID-19 infection: A case report. J Clin Neurosci 76: 233-235.

32. VD Krishna, K Wu, AM Perez, JP Wang (2016) Giant magnetoresistance-based biosensor for detection of influenza A virus, Front. Microbiol 7: 400.

33. ST Jones (2020) How materials can beat a virus. J Mater Sci 55: 9148 9151.

34. M Coisson, G Barrera, F Celegato, L Martino, SN Kane, et. al. (2017) Hysteresis losses and specific absorption rate measurements in magnetic nanoparticles for hyperthermia applications. Biochimica et Biophysica Acta 1861: 1545-1558.

35. S Gul, MA Yousuf, A Anwar, MF Warsi, FO Agboola, et al. (2020) Al-substituted zinc spinel ferrite nanoparticles: Preparation and evaluation of structural, electrical, magnetic and photocatalytic properties. Ceramics Int 46: 14195-14205.

36. X Han, T Chen, R Li, F Cheng, M Zhang, M Guo, et al. (2019) Hydrothermal temperature effect on microstructure evolution and Fenton-like catalytic performance of spinel ferrite (Mg, Ni) (Fe, Al)204 synthesized from saprolitic nickel laterite. Colloids and Surfaces A 568: 11-19.

37. MR Hoffmann, S Martin, W Choi, DW Bahnemann (1995) Environmental applications of semiconductor photocatalysis. Chem Rev 95: 69-96.

38. K Jahanara, S Farhadi (2019) A magnetically separable plate-like cadmium titanate-copper ferrite nanocomposite with enhanced

\section{Your next submission with Juniper Publishers will reach you the below assets}

- Quality Editorial service

- Swift Peer Review

- Reprints availability

- E-prints Service

- Manuscript Podcast for convenient understanding

- Global attai nment for your research

- Manuscript accessibility in different formats

( Pdf, E-pub, Full Text, Audio)

- Unceasing customer service

Track the below URL for one-step submission https://juniperpublishers.com/online-submission.php 